Fukushima J. Med. Sci., Vol. 56, No. 1, 2010

[Research Report]

\title{
ASSOCIATION BETWEEN MATERNAL FEELING ABOUT PREGNANCY AND CHILD'S LIFESTYLE
}

\author{
TOMOKO SAITO ${ }^{1)}$, AYA GOTO ${ }^{1)}$, HIROHIDE YOKOKAWA ${ }^{1)}$, \\ YOSHIAKI SATO $^{2)}$ and SEIJI YASUMURA ${ }^{1)}$ \\ ${ }^{1)}$ Department of Public Health, Fukushima Medical University School of Medicine, ${ }^{2)}$ Health Promotion Division, \\ City of Nihonmatsu (At the time of manuscript writing)
}

(Received December 17, 2009, accepted April 7, 2010)

\begin{abstract}
The number of children with undesirable lifestyles has recently increased. We tested the hypothesis that maternal feelings about pregnancy might be associated with their attitude towards promoting healthy lifestyles in their children. We used a city database collected from guardians of 204 randomly selected children aged 1 to 3 years in Nihonmatsu City, Fukushima. Maternal feeling about pregnancy was measured using a 10-point scale, and a child lifestyle score was calculated as the sum of desirable lifestyle habits (sleeping, eating, watching TV/videos, and tooth brushing). Associations between maternal feeling and her child's lifestyles were examined with multiple logistic regression analysis. For all lifestyle items, proportion of children with undesirable lifestyle habits was higher in the "unhappy group" (those who scored 1 to 9) than in the "happy group" (those who scored 10). In particular, a child's short sleeping hours (odds ratio $[\mathrm{OR}]=3.01$ ) and lifestyle score of less than $3([\mathrm{OR}]=3.60)$ were significantly associated with unhappy feelings. This was apparent among mothers aged 29 (median age) or younger. Our results indicate an association between a mother's unhappy feelings about pregnancy and her child's undesirable lifestyle, especially among relatively younger mothers. These findings provide public health implications important for early familial intervention to improve children's lifestyles.
\end{abstract}

Key words : Child, lifestyle, pregnancy, mothers, Japan

\section{INTRODUCTION}

In recent years, children's lifestyles have changed drastically in Japan ${ }^{11}$. According to a national survey conducted in 2000 by The Japanese Society of Child Health, children's nocturnal sleep durations have become shorter due to later bedtimes ${ }^{2}$. Bedtime for the more than half of children ( $54.4 \%$ for 1 -year olds, $59.2 \%$ for 2 -year olds, $51.7 \%$ for 3 -year olds)

齋藤智子, 後藤あや, 横川博英, 佐藤義昭, 安村誠司

Corresponding author : Tomoko Saito E-mail: saitomo8@fmu.ac.jp

http://fmu.ac.jp/lib/F-igaku/ http://www.sasappa.co.jp/online/ 
was 10 p.m. or later, which represents a more than two-fold increase since $1980^{2)}$. An increase in time spent watching TV/videos has also been reported, with about $70 \%$ of children watching TV/videos more than 2 hours per day ${ }^{2}$. The proportion of children who play inside the house has also increased ${ }^{2}$. The Nutrition Surveillance of Young Children conducted in 2005 reported that the proportion of children who have an unbalanced diet has nearly doubled over the last decade, and about $40 \%$ of children do not eat vegetables every $\mathrm{day}^{3}$. Along with these undesirable lifestyle habits, there is a nationwide increase in childhood obesity, which contribute to development of lifestyle disease during childhood and adulthood $^{4)}$.

Children's lifestyles are largely influenced by their familial environment, such as parental lifestyles, parent education, and socioeconomic status. Family structure, mother's work status, and parental physical activity have been reported as correlates of children's physical activity ${ }^{5,6}$. Previous studies have shown that parental dietary behaviors, parental awareness of dietary behaviors, and child-feeding practices influence their children's development of dietary behaviors ${ }^{7,8}$.

The role of maternal mental status has received increased attention in Japan due to the government's intention to improve the parenting environment and in turn, increase the declining birth rate. Studies, mostly from western countries, have reported that maternal feelings about the pregnancy are associated with negative lifestyle practices, such as drinking and smoking during pregnancy ${ }^{9)}$. Furthermore, these feelings influence children's psychomotor development, and emotional and attentional regulation ${ }^{10)}$. Researchers in Japan have begun investigating long-term influences of maternal mental state on children's psychological and physical development ${ }^{11)}$, but have not examined children's lifestyles, even though prevention of lifestyle-related diseases is the main goal of the government's national health $\operatorname{plan}^{12)}$.

In an attempt to investigate factors which may aid in early family intervention to improve children's lifestyles, we analyzed the association between Japanese maternal feelings about pregnancy and children's lifestyles using existing community data from one city in Japan. The following four lifestyle indicators available in the dataset were included in the present analyses : child's sleeping hours, mother's attitudes towards her child's dietary habits, time spent watching TV/video, and tooth brushing. Selection of these lifestyle indicators was based on previous review studies on childhood obesity which indicates physical activity, sedentary behavior (e.g., watching television and reading), dietary patterns, and sleeping hours as fundamental components of a child's lifestyle ${ }^{13,14)}$. In addition, child's dental habits have been reported to be associated with maternal cognitive, behavioral, and psychosocial factors ${ }^{15)}$.

\section{METHODS}

Data were obtained from a database developed to frame a healthy lifestyle support plan in Nihonmatsu City, Fukushima Prefecture, Japan ${ }^{16)}$. The database contained responses to a health survey conducted in accordance to the national health plans ("Healthy Japan 21" and 
“Healthy and Happy Family 21"). Guardians of children aged 1 to 3 years were selected from a residence registry as of November 1, 2006 through single-stage random sampling. With a sampling ratio of $13 \%$, which was set considering the survey feasibility and assuming the response rate to be $50 \%, 204$ out of 1566 children were selected. Anonymous, selfadministered questionnaires were distributed and collected via mail. In the present analysis, we excluded data for which responses had been made by someone other than the mother. Use of the database was approved by the city, and we worked in accordance with the Ethical Guidelines for Epidemiological Studies established by the Japanese government.

The questionnaire, which was jointly developed by the city and our team in the Department of Public Health at Fukushima Medical University, consisted of items pertaining to socio-demographic background, feelings about pregnancy, maternal antenatal health behavior and knowledge, child-rearing conditions, and the child's lifestyle. Respondents rated their feelings about pregnancy on a 10-point scale ranging from 1 (very unhappy) to 10 (very happy), which was used in the National Survey of Family Growth (NSFG) in the United States. The measurement was translated into Japanese as described previously ${ }^{17}$. In this study, respondents were dichotomized into two groups by their score: the happy group (score of 10) and the unhappy group (score of 1-9). This classification was based on a previous survey report by NSFG, in which respondents scoring 10 were treated as one group while those scoring 1 to 9 were classified into four groups ${ }^{18)}$.

Questions regarding children's lifestyles were cited from the Child Health Survey $2000^{2)}$. For each lifestyle item, we defined "undesirable" habits as follows : sleeping less than 11.5 hours/day, watching TV 3 or more hours/day, and mothers answering "no" to questions asking whether they pay attention to their children's dietary habits and whether they brush their children's teeth every day. Median values were used to dichotomize sleeping hours and time spent watching TV/video. Each desirable habit was counted as 1 point, and we defined the total lifestyle score as the sum of the four habits. This type of scoring is similar to the Health Practice Index in the Alameda study and our previous study ${ }^{19,20}$.

We examined the association of unhappy feeling about the pregnancy (score of 1-9) with undesirable lifestyle indicators by using multiple logistic regression analysis. We controlled for seven factors which were previously reported to associate with maternal parenting behavior $^{21-23)}$ and available in our dataset : child's age, sex, living with siblings, living with grandparents, mother's age at delivery, mother's confidence in child rearing, and father's cooperation in child rearing. To further explore the influences of confounding factors, we conducted stratified analyses, and tested for homogeneity when needed. Analyses were performed using Dr. SPSS II statistical software for Windows (SPSS Japan Inc., Tokyo).

\section{RESULTS}

The total number of respondents was 128 (response rate $=62.7 \%$ ). We analyzed 117 and excluded 11 because the questionnaires had been completed by people other than the mothers.

Characteristics of respondents are shown in Table 1. Proportion of boys was $52.1 \%$ and 
Table 1. Characteristics of respondents

\begin{tabular}{|c|c|}
\hline & $\begin{array}{c}\text { Mean (SD) or } N(\%) \\
{[N=117]}\end{array}$ \\
\hline \multicolumn{2}{|l|}{ Parents } \\
\hline Maternal age at delivery & $29.0(4.7)$ \\
\hline Paternal age at delivery & $31.4(6.0)$ \\
\hline \multicolumn{2}{|c|}{ Maternal confidence in child rearing } \\
\hline Have confidence & $20(17.1)$ \\
\hline No confidence & $97(82.9)$ \\
\hline \multicolumn{2}{|c|}{ Paternal cooperation in child rearing } \\
\hline Cooperative & $103(88.0)$ \\
\hline Not cooperative & $12(10.3)$ \\
\hline \multicolumn{2}{|l|}{ Children } \\
\hline \multicolumn{2}{|l|}{ Sex } \\
\hline Boy & $61(52.1)$ \\
\hline Girl & $56(47.9)$ \\
\hline \multicolumn{2}{|l|}{ Age (years) } \\
\hline 1 & $32(27.4)$ \\
\hline 2 & $36(30.8)$ \\
\hline 3 & $49(41.9)$ \\
\hline \multicolumn{2}{|l|}{ Cohabitation } \\
\hline \multicolumn{2}{|l|}{${ }^{\dagger}$ Grandparents } \\
\hline Yes & $66(56.4)$ \\
\hline No & $49(41.9)$ \\
\hline \multicolumn{2}{|l|}{ †Siblings } \\
\hline Yes & $35(29.9)$ \\
\hline No & $80(68.4)$ \\
\hline
\end{tabular}

${ }^{\dagger}$ : Totals across columns for these items do not add up to the total number indicated in top row because of missing data.

children's age distribution was as follows : 1 year old 27.4\%, 2 years old 30.8\%, and 3 years old $41.9 \%$. Median age of mothers at delivery was 29 years (range $=18-45$ ). Percentage of mothers who rated their feeling about the pregnancy as a 10 (classified as the "happy group") was $63.2 \%$. Children slept a median of 11.5 hours/day (range $=9.75-13.5$ ), including naps. Only $47.0 \%$ of children spent less than 2 hours/day watching TV/video, while $24.8 \%$ spent more than 3 hours/day watching TV/video. Median lifestyle score was 3 (range $=0-4$ ).

Associations between maternal feeling about pregnancy and child's lifestyle are shown in Table 2. For all items, the proportion of mothers giving undesirable answers was higher in the unhappy group than the happy group. In particular, we observed significant associations for not brushing the child's teeth every day (odds ratio $[\mathrm{OR}]=2.72$ ) and for overall low lifestyle score $(\mathrm{OR}=2.52)$ in bivariate analyses. After adjusting for seven factors previously reported to be associated with parenting, child's dental habit did not remain significant, and the ORs of lifestyle score and child's sleeping hours increased. An additional analysis showed that the proportion of children whose bedtime was 10 p.m. or later was slightly 


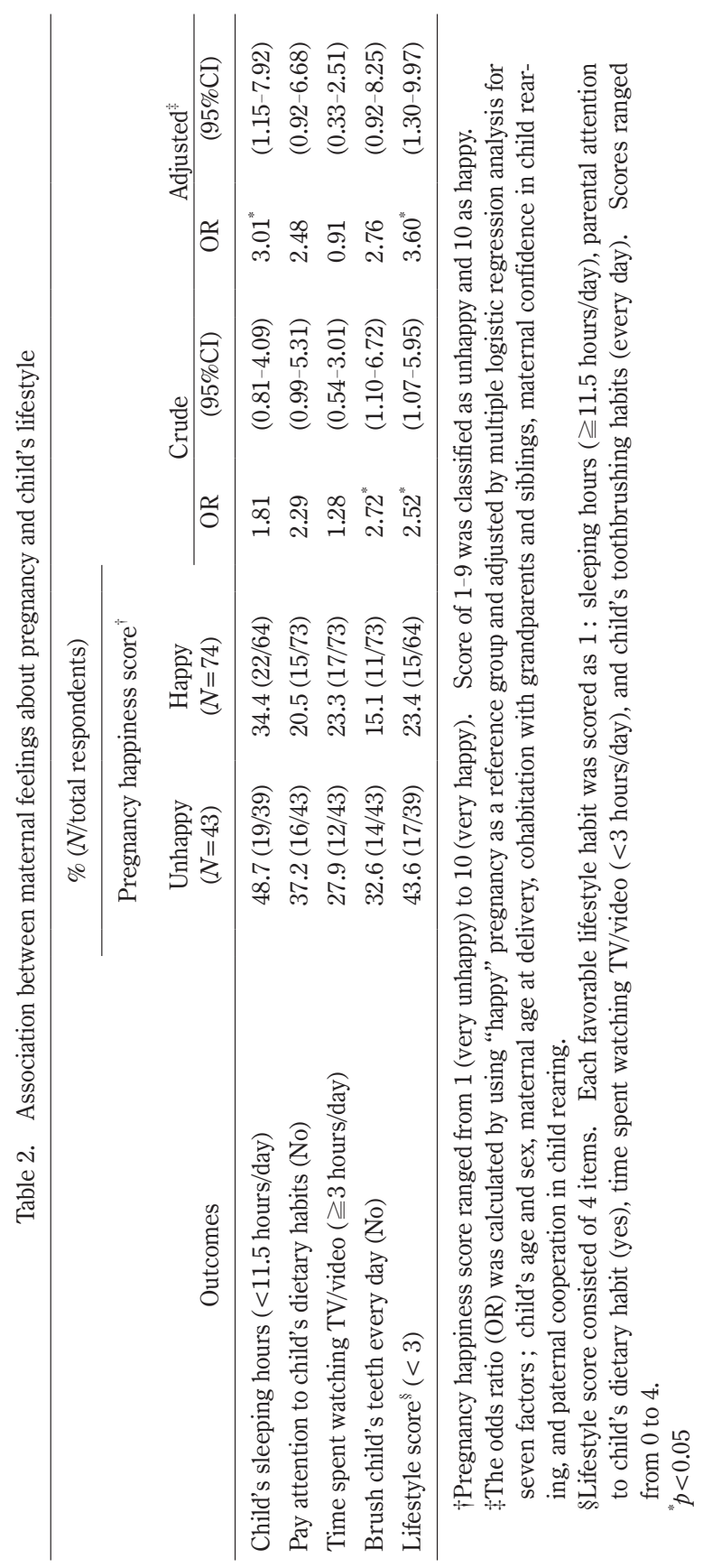


higher in the unhappy group (27.9\%) compared to the happy group (21.9\%), but not significant.

By performing bivariate logistic regression analyses entering one adjusting factor at a time, we found that an increase in OR of the unhappy group (against the happy group) for sleeping hours and lifestyle score occurred only when we adjusted for maternal age at delivery. We subsequently carried out stratified analyses according to maternal median age at delivery where groups were equal to or younger than 29 years of age $(N=62)$ and older than 29 years of age $(N=48)$. Feelings about pregnancy were significantly associated with child's sleeping hours (Fisher's exact test, $p=0.04)$ and lifestyle scores $(p=0.01)$ in the group of women who were 29 or younger at delivery (Table 3). Additionally, although not statistically significant, proportion of longer time spent watching TV/video was higher in the happy group compared to the unhappy group among older mothers. Statistical significance of homogeneity tests between the two age groups was 0.11 for sleeping hours and less than 0.04 for the lifestyle score.

\section{DISCUSSION}

The present study represents a pioneer trial in Japan to facilitate research on early

Table 3. Association between maternal feelings about pregnancy and child's lifestyle by maternal age.

\begin{tabular}{lccc}
\hline & \multicolumn{2}{c}{$N(\%)$} & \\
\cline { 2 - 3 } & \multicolumn{2}{c}{ Pregnancy happiness score } & \multirow{2}{*}{$P$ value $^{\dagger}$} \\
Aged 29 years or younger & Unhappy & Happy & \\
\hline Child's sleeping hours (<11.5 hours/day) & $(N=24)$ & $(N=38)$ & \\
Pay attention to child's dietary habits (No) & $12(57.1)$ & $8(26.7)$ & 0.04 \\
Time spent watching TV/video ( $\geq 3$ hours/day) & $9(37.5)$ & $6(15.8)$ & 0.07 \\
Brush child's teeth every day (No) & $8(33.3)$ & $9(23.7)$ & 0.56 \\
Lifestyle score $(<3)$ & $7(29.2)$ & $5(13.2)$ & 0.19 \\
\hline
\end{tabular}

\begin{tabular}{lccc} 
& \multicolumn{2}{c}{$N(\%)$} & \\
\cline { 2 - 3 } & \multicolumn{2}{c}{ Pregnancy happiness score } & \multirow{2}{*}{$\begin{array}{c}\text { Happy } \\
\text { Aged 30 years or older }\end{array}$} \\
\cline { 2 - 3 } & $\begin{array}{c}\text { Unhappy } \\
(N=15)\end{array}$ & $(N=33)$ & \\
\hline Child's sleeping hours $(<11.5$ hours/day) & $6(42.9)$ & $12(38.7)$ & 1.00 \\
Pay attention to child's dietary habits (No) & $5(33.3)$ & $8(25.0)$ & 0.73 \\
Time spent watching TV/video ( $\geqq 3$ hours/day) & $1(6.7)$ & $8(25.0)$ & 0.24 \\
Brush child's teeth every day (No) & $5(33.3)$ & $4(12.5)$ & 0.12 \\
Lifestyle score $(<3)$ & $5(35.7)$ & $9(29.0)$ & 0.73 \\
\hline
\end{tabular}

$\dagger$ Fisher's exact test was used.

Statistical significance of homogeneity tests between the two age groups was 0.11 for sleeping hours and less than 0.04 for lifestyle score. 
development of children's lifestyles. Although the findings are preliminary, they indicate a possible association between unhappy maternal feelings about pregnancy and children's lifestyles in this sample, especially among young mothers. Interestingly, we found a significant difference between younger and older mothers. Results from the test of homogeneity statistically confirmed this difference, especially for the lifestyle score. Some features of younger mothers compared to older mothers have been reported. Proportion of unintended pregnancy, which is significantly associated with maternal unhappiness about pregnancy ${ }^{9)}$, tends to be higher among younger mothers ${ }^{24)}$. Moreover, younger mothers in previous studies not only evaluated their parenting behavior lower, but also reported poorer self-rated health, more sleep problems, and greater fatigue than older mothers ${ }^{25-27)}$.

Our results provide public health implications important for familial early intervention to improve children's lifestyles. Pregnant women in Japan are required to report their pregnancies to a local governmental office and receive a Mother and Child Health Handbook, in which they record results of antenatal care visits and child growth. While the procedure is simply administrative in most municipalities, individual health counseling is provided in some municipalities ${ }^{28}$. This opportunity is the only chance to contact every pregnant mother during the early stages of pregnancy, which can be used to assess the mother's feeling about her pregnancy and provide high-risk mothers with lifestyle instructions.

Moreover, antenatal classes and postnatal parenting classes organized at hospitals, clinics, and municipal health centers can be good opportunities to increase a mother's awareness as the gatekeeper for her family's health. Maternal environment during the prenatal stages in particular has long been recognized by pediatricians in Fukushima as an important component contributing to children's health ${ }^{29)}$. However, it has not been fully addressed either as a form of epidemiologic research or in clinical practice. A closer relationship between antenatal and postnatal services, which would require concerted efforts among midwives, public health professionals, and medical professionals, is needed in order to facilitate smooth transitions from antenatal to postnatal health care. Additionally, as maternal feelings of happiness were associated with their child's desirable lifestyles, mental support for mothers to promote positive feelings during pregnancy and parenting are recommended. Currently, the local government of Fukushima prefecture is trying to improve mental support for mothers and their families ${ }^{30)}$. The above conclusions were derived from discussions of our study's findings with Nihonmastu City officers and public health nurses.

Three major limitations of this study should be noted. The first is recall bias. Maternal recall of feelings at the time of pregnancy may be influenced by her current parenting situa$\operatorname{tion}^{31)}$, and thus a prospective design study should be employed in future studies. Second, the sample size was small with a response rate of $62.7 \%$. This limits further discussion regarding reverse outcomes in the older group. Third, our data was limited to existing community data from one city. Unfortunately, we could not obtain information on parental educational and financial statuses. Furthermore, questions about parental lifestyle habits were not included in the survey, thus no conclusions on potential correlations between child's lifestyle and parental lifestyle can be drawn. Finally, cross-validation with data from other regions in Japan would be required for generalization of our results. To confirm the association between 
maternal feeling about pregnancy and child's lifestyle, further studies are required.

\section{ACKNOWLEDGMENTS}

We thank Emeritus Professor Hitoshi Suzuki of the Department of Pediatrics and Dr. Takumi Kawai of the Department of Public Health at Fukushima Medical University School of Medicine for their insightful comments made from their perspectives as pediatricians.

\section{REFERENCES}

1. Ministry of Education, Culture, Sports, Science and Technology. Kodomo-no-seikatsu-shukanzukuri shien-jigyou,

Available at : <http://www.mext.go.jp/a_menu/hyouka/kekka/08100105/011.htm>.

Accessed October 6, 2009. (in Japanese)

2. The Japanese Society of Child Health. Child Health Survey 2000.

Available at : < http://www.aiiku.or.jp/aiiku/jigyo/contents/kanren/kr0108/kr0108.htm>.

Accessed February 12, 2009. (in Japanese)

3. Ministry of Health, Labour and Welfare. Equal Employment, Children and Families Bureau. Infants Nutrition Survey 2005.

Available at : <http://www.mhlw.go.jp/houdou/2006/06/dl/h0629-1b.pdf > .

Accessed February 12, 2009. (in Japanese)

4. WHO. Childhood overweight and obesity.

Available at : < http://www.who.int/dietphysicalactivity/childhood/en/index.html >.

Accessed December 23, 2008.

5. Van Der Horst K, Paw MJ, Twisk JW, Van Mechelen W. A brief review on correlates of physical activity and sedentariness in youth. Med Sci Sports Exerc, 39 : 1241-1250, 2007.

6. Sekine M, Kanayama H, Kagamimori S. Associations of social and family characteristics with physical inactivity in a Japanese birth cohort. (in Japanese) Kenkouikagaku Kennkyujosei Ronbunshu, 22: 62-69, 2007.

7. Scaglioni S, Salvioni M, Galimberti C. Influence of parental attitudes in the development of children eating behavior. Br J Nutr, 99(Suppl. 1) : S22-S25, 2008.

8. Tsukahara Y. Developmental characteristics and relationship between the dietary awareness of parents and the dietary behavior and health condition of children. (in Japanese) The Japanese Journal of Nutrition, 61 : 223-233, 2003.

9. Blake SM, Kiely M, Gard CC, El-Mohandes AA, El-Khorazaty MN; NIH-DC Initiative. Pregnancy intentions and happiness among pregnant black women at high risk for adverse infant health outcomes. Perspect Sex Reprod Health, 39 : 194-205, 2007.

10. DiPietro JA, Novak MF, Costigan KA, Atella LD, Reusing SP. Maternal psychological distress during pregnancy in relation to child development at age two. Child Dev, 77 : 573-587, 2006.

11. Maruyama A, Ohzeki T, Anme T. Factors associated with growth, social adjustment, behavioral problems and health status among 2-years-old toddlers attending day care centers. (in Japanese) Kosei No Shihyo, 53(6) : 24-33, 2006.

12. Ministry of Health and Welfare. Healthy Japan 21 Working Group. National Health Promotion Movement in the 21st Centry (Healthy Japan 21) Report. (in Japanese) Tokyo, 2000.

13. Summerbell CD, Waters E, Edmunds L. Intervention for preventing obesity in children. Cochrane Database of Systematic Reviews, 3, 2009.

14. Patel SR, Hu FB. Short sleep duration and weight gain : a systematic review. Obesity, 16: 643- 
$653,2008$.

15. Finlayson TL, Siefert K, Ismail AI, Sohn W. Maternal self-efficacy and 1-5-years-old children's brushing habits. Community Dent Oral Epidemiol, 35 : 272-281, 2007.

16. Nihonmatsu City. Nihonmatsu-shi Kenkouzoushin-keikaku.

Available at : <http://www.city.nihonmatsu.lg.jp/kurashi/hoken/kenkou/kenkouzousin-keikaku/ zousinkeikaku-top.html>

Accessed March, 2010. (in Japanese)

17. Goto A, Yasumura S, Yabe J, Anazawa Y, Hashimoto Y. Association of pregnancy intention with parenting difficulty in Fukushima, Japan. J Epidemiol, 15 : 244-246, 2005.

18. Chandra A, Martinez GM, Mosher WD, Abma JC, Jones J. Fertility, family planning, and reproductive health of U.S. women : data from the 2002 National Survey of Family Growth. Vital and Health Statistics Series 23, No 25. Centers for Disease Control and Prevention, 2005.

19. Belloc MB, Breslow L. Relationship of physical health status and health practices. Prev Med, 1 : 409-421, 1972.

20. Yokokawa H, Goto A, Abe Y, Suzuki S, Yasumura S. Lifestyle characteristics and 3-year mortality of Japanese with self-reported diabetes. Health Soc Care Community, 16 : 614-620, 2008.

21. Kato M, Tsuda T. A Longitudinal Study on Maternal Feelings and Behavior during the Early Years of Child Rearing. (in Japanese) Shoni Hoken Kenkyu, 60 : 780-786, 2001.

22. Yahata Y, Hata E, Sato C, Iwanaga T. Investigation of factors affecting psychological depression in child- rearing mothers. (in Japanese) Nippon Koshu Eisei Zasshi, 46 : 521-530, 1999.

23. Okamoto K, Nakamura Y, Yamaguchi M, Okuyama N, Simegi M, Watanabe T. A Study on the Perceived Fatigue Levels of Child-rearing Mothers and the Participation in father's Child Care. (in Japanese) Shoni Hoken Kenkyu, 61 : 692-700, 2002.

24. Mohllajee AP, Curtis KM, Morrow B, Marchbanks PA. Pregnancy intention and its relationship to birth and maternal outcomes. Obstet Gynecol, 109 : 678-686, 2007.

25. Floderus B, Hagman M, Aronsson G, Marklund S, Wikman A. Self-reported health in mothers : the impact of age, and socioeconomic conditions. Women Health, 47 : 63-86, 2008.

26. Mistry R, Stevens GD, Sareen H, De Vogli R, Halfon N. Parenting-related stressors and selfreported mental health of mothers with young children. Am J Public Health, 97 : 1261-1268, 2007.

27. Fox RA, Platz DL, Bentley KS. Maternal factors related to parenting practices, development expectations, and perceptions of child behavior problems. J Genet Psychol, 156 : 431-441, 1995.

28. Goto A, Yasumura S, Yabe J, Reich MR. Addressing Japan's fertility decline : influences of unintended pregnancy on child rearing. Reprod Health Matters, 14 : 191-200, 2006.

29. Shunsei-kai. Ikeda Ryuichi Sensei no Tsuioku. (in Japanese) 19-20, 1979.

30. Fukushima Prefecture. Utsukushima Kodomo Yume Plan. (in Japanese) 41-42, 2005.

31. Bankole A, Westoff CF. The consistency and validity of reproductive attitudes : evidence from Morocco. J Biosoc Sci, 30 : 439-445, 1998. 
Appendix

Questions from the Nihonmatsu City health survey ${ }^{16)}$ analyzed in the present study.

\begin{tabular}{|c|c|c|}
\hline \multirow[t]{4}{*}{ Socio-demographic background } & Q1-1 & $\begin{array}{l}\text { What is your child's sex? } \\
\text { (1. Male } 2 . \text { Female) }\end{array}$ \\
\hline & Q1-2 & $\begin{array}{l}\text { How old is your child as of November } 1,2006 ? \\
(\quad) \text { years old }\end{array}$ \\
\hline & Q1-3 & $\begin{array}{l}\text { With whom does your child currently live? } \\
\begin{array}{lll}\text { (1. Mother }(\quad) \text { years old } & \text { 2. Father }(\quad) \text { years old } \\
\text { 3. Grandparents } & \text { 4. Siblings } & \text { 5. Others })\end{array}\end{array}$ \\
\hline & Q1-4 & $\begin{array}{l}\text { Who is answering this survey sheet? Please select one in } \\
\text { relation to the index child. } \\
\text { (1. Mother } \quad \text { 2. Father } \quad 3 \text {. Grandparent } \quad \text { 4. Others) }\end{array}$ \\
\hline $\begin{array}{l}\text { Maternal feeling about preg- } \\
\text { nancy }\end{array}$ & Q3 & $\begin{array}{l}\text { How did you feel at the time you realized you were pregnant? } \\
\text { Please circle the number that best describes your feelings : } \\
\text { Very } 1 \\
\text { unhappy }\end{array}$ \\
\hline $\begin{array}{l}\text { Maternal confidence in child } \\
\text { rearing }\end{array}$ & Q14 & $\begin{array}{l}\text { Are there any moments when you don't feel confident about } \\
\text { child rearing? } \\
\left(\begin{array}{lll}1 . \text { Yes } & 2 . \text { No } & 3 . \text { Not sure })\end{array}\right.\end{array}$ \\
\hline $\begin{array}{l}\text { Paternal cooperation in child } \\
\text { rearing }\end{array}$ & Q16 & $\begin{array}{l}\text { Do you think the child's father is cooperative in child rearing? } \\
\begin{array}{llll}\text { (1. Always } & 2 . \text { Sometimes } & 3 . \text { Rarely } \quad 4 . \text { Not sure })\end{array}\end{array}$ \\
\hline \multirow[t]{6}{*}{ Child's lifestyle } & Q26-1 & $\begin{array}{l}\text { Does your child eat breakfast almost every day? } \\
\text { (1. Yes } 2 \text {. No ) }\end{array}$ \\
\hline & Q26-2 & $\begin{array}{l}\text { Do you have anything that you pay attention to with regard to } \\
\text { your child's dietary habits? } \\
\left(\begin{array}{ll}\text { (1. Yes } & 2 . \text { No ) }\end{array}\right.\end{array}$ \\
\hline & Q27 & $\begin{array}{l}\text { How often does your child brush their teeth? } \\
\text { (Every day (1. Once } \quad 2 . \text { Twice } \quad 3 . \text { More than three times ) } \\
\begin{array}{lll}\text { 4. Sometimes } & 5 . \text { Never })\end{array}\end{array}$ \\
\hline & Q28 & $\begin{array}{l}\text { When are your child's bedtime and wake-up time? } \\
\text { Bedtime ( ) o'clock } \\
\text { Wake-up time ( ) o'clock }\end{array}$ \\
\hline & Q29 & $\begin{array}{l}\text { Does your child take a nap? } \\
(1 . \text { Yes }---(\quad) \text { hours } \quad 2 . \text { No })\end{array}$ \\
\hline & Q30 & $\begin{array}{l}\text { How many hours does your child spend each day watching } \\
\text { TV/videos? } \\
\text { (1. Less than } 1 \text { hour } 2.1-2 \text { hours } 3.2-3 \text { hours } \\
\text { 4. } 3 \text { - } 4 \text { hours } 5 \text {. More than } 4 \text { hours ) }\end{array}$ \\
\hline
\end{tabular}

Original questionnaire was in Japanese and translated for the purpose of this report. 